\title{
Novel Approaches to Reduce Substrate Dependency of DUV Chemically Amplified Photoresist
}

\author{
Jun-Sung Chun*, Cheol -Kyu Bok and Ki-Ho Baik \\ Hyundai Electronics Ind. Co., Ltd., Memory RED Division \\ San136-1, Ami-ri, Bubal-eub, Ichon-si, Kyung ki-do, 467-701, Korea \\ *Current address; ASM lithography, 463-070, 3fl, Kwangmyung plaza, 328-2 \\ Yatap-dong, Pundang-ku, Sungnam-si, Kyung-ki, Korea
}

In the case of silicone nitride film acid treatment can eliminate resist scum so that we can get clean resist patterns. The acid used, called Clean D treatment for photoresist strip, normally consists of a mixture of surphuric acid $\left(80 \% \mathrm{H}_{2} \mathrm{O}\right)$ and hydrogen peroxide $(80 \%$ $\mathrm{H}_{2} \mathrm{O}$ ). ESCA(Electron Spectroscopy by Chemical analysis) was used to examine the surface of the films after cleaning with the acid treatment and to monitor the change in atomic percents of the films with time. Considering all the analytical data, this acid treatment to silicon nitride makes the film surface oxide-rich resulting in forming barrier layer between substrates and protons from PAG(Photo Acid Generator). For BPSG(BoroPhosphorous Silicate Glass) films the mechanism of the formation of resist foot is quite different from that of silicon nitride. Improved resist profiles on BPSG were obtained by the dehydration bake. Therefore it could be speculated that the formation of resist scums on silicon nitride films are due to the nitrogen in films and on the BPSG moisture. Surface pretreatment by oxygen plasma was also reviewed. It is quite certain that these two methods, acid and $\mathrm{O}_{2}$ plasma treatments are very effective, economical and simple process. However, there are delay time effects after pretreating films unlike other conventional oxide capping layers. This problem will be also discussed in details.

Key words: substrate dependency, acid treatment, resist scum \& foot, dehydration

\section{Introduction}

Microlithography has been driven by the miniaturization of the semiconductor devices. DRAMs are the driving forces of IC's development and are the technology indicator for advanced device manufacturing. DUV lithography such as $\mathrm{KrF}$ and $\mathrm{ArF}$ will be a product-worthy technology. For DUV lithography, KrF excimer laser source and chemically amplified resist has been developed for production. Much progress has been demonstrated in the field of transparent chemically amplified resists with high sensitivity and stability between exposure and post exposure bake. New DUV resist has been proven their potentials for feature size down to $200 \mathrm{~nm}$ lines/spaces patterns using high NA(0.6) without $C$. D variations after 6 hours delay time. However, for the implementation to the real device, these new chemically ampli- fied resists should overcome the various substraterelated problems.

Unlike conventional novolac based i-line resist, DUV chemically amplified photoresists produce protons during the exposure and catalyze photochemical reaction to delineate fine patterns. During PEB(Post Exposure Bake) the chemically activated protons diffuse into the exposed areas. Due to its inherent instability protons are likely to be neutralized by atmospheric impurities forming t-top profile. Continuous improvement have been made in eliminating the problems such as cluster tool equipped with chemical filter,[1] RTC(Resist Top Coating),[2] annealing concept to reduce free volumes in resist system, [3] etc.

Another issue to be addressed is the substrate dependency of chemically amplified resist, especially 
on silicon nitride and BPSG films. It is considered as a kind of chemical reaction between films and protons from PAG via unidentified chemistry resulting in severe resist scum and foot. Several attempts to resolve the problems have been reported. A. Usujima reported that resist footing problems on silicon nitride could be solved by pretreating the films with oxygen plasma.[4] K. R dean published that applying oxide capping layer on TiN films reduced resist footing. [5] Resist footing problems have been a major issues to be solved. Hitherto, it has been not been reported about resist scumming problems on silicon nitride films. It is worse than resist foot and indistinguishable until we observe the cross-sectional SEM micrographs. Fig. 1 shows scums of three different DUV chemically amplified positive photoresists on silicone nitirde films. These problems also can be resolved by adopting various surface pretreating methods.

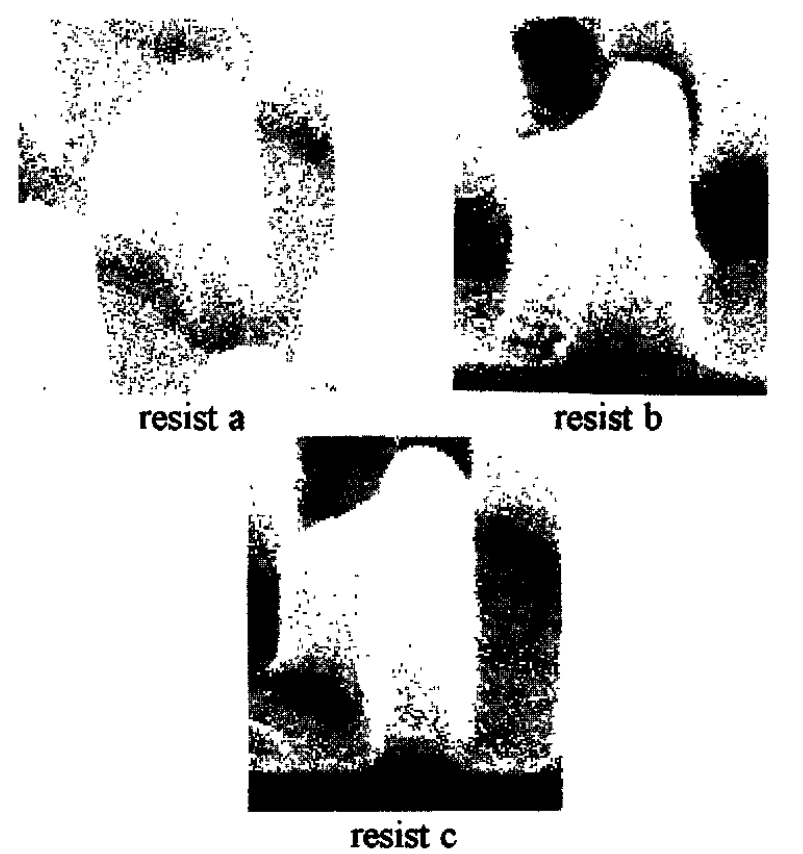

Fig.1 Cross-sectional SEM micrographs of three different DUV resist on $\mathrm{Si}_{3} \mathrm{~N}_{4}$ films

In this paper, we suggest simple solutions for scum and foot-free resist profiles on silicon nitride and BPSG films and also review various surface pretreating methods such as conventional oxide capping layer, oxygen plasma treatment comparing their process feasibilities and capabilities.

\section{Experimentals}

The wafers were coated with three different DUV positive chemically amplified resist(various rpm for $30 \mathrm{sec}$ and baked on hot plate) resulting in resist thickness of $800 \mathrm{~nm}$. Exposures were carried out on $\mathrm{KrF}$ Excimer stepper(0.55NA, 0.55 partial coherence factor). The processes were carried out on the clusters interfaced with stepper and track equipped with chemical filtration system. No overcoating materials were used in this experiment. Cross-sectional profiles were obtained on SEM micrographs. $230 \mathrm{~nm}$ of silicon nitride and $1000 \mathrm{~nm}$ of BPSG films on (100)oriented 8 inch wafers were used. Oxygen plasma treatment was carried out on PECVD furnace and dehydration bake on convection oven. ESCA was used to monitor surface atomic changes of substrates by various pretreatment.

\section{Results and discussions}

\section{1. silicon nitride films}

At the first place resist scums on silicon nitride film was not entirely recognized until we cleave the wafers for cross-sectional SEM. Surprisingly enough, all positive DUV chemically amplified resist, as far as evaluated, produce their scums. Fig. 2 shows that various trials to reduce resist scums such as hard bake at convection oven, longer development time and higher PEB temperature that usual process conditions, did not solve the problem. Also, as shown in fig. 1 and 2, resist scums might come from film itself, not from resist or process.

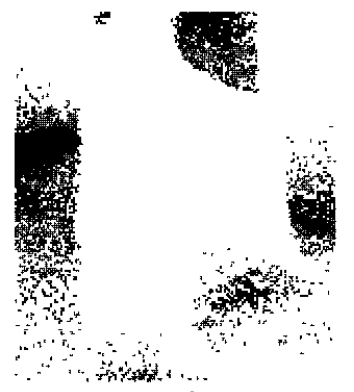

a)

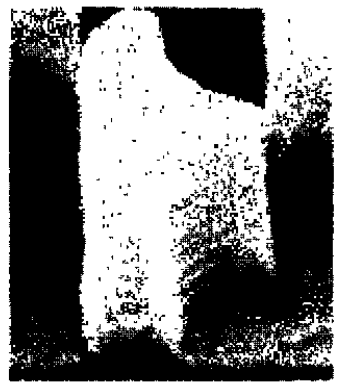

b)

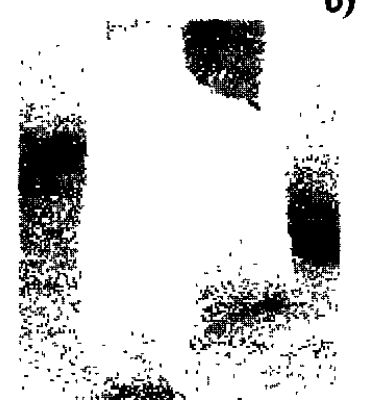

c)
Fig.2 Various trials for reducing scums on $\mathrm{Si}_{3} \mathrm{~N}_{4} ;$ a) $500{ }^{\circ} \mathrm{C}$ of hard bake at oven before resist coating, b) 120 
sec of development time, c) higher PEB temperature $\left(160^{\circ} \mathrm{C}\right)$; normally $140^{\circ} \mathrm{C}$

It is well known that resist footing and scumming problems on silicon nitride is closely related with the thickness of the films. A. Usujima et al found in their experiment that the improved resist profile was obtained on $95 \mathrm{~nm}$ and $150 \mathrm{~nm}$ of silicon nitride.[4] However, as fig. 3 shows the uniformity of silicon nitride of 8 inch Si wafer, their results do not fit our process.

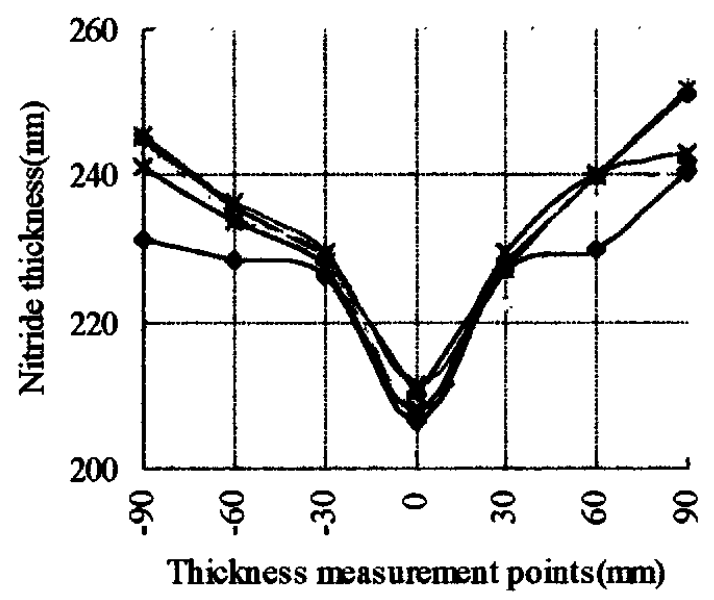

Fig. 3 Thickness uniformity of $\mathrm{Si}_{3} \mathrm{~N}_{4}$ on 8 inch $\mathrm{Si}$ wafer; $\mathrm{X}$-Axis( $\mathrm{Y}$-axis was found to have the same thickness uniformity)

Finally it is concluded that capping methods on silicon nitride film is the only way for scum and footfree resist profiles. Fig. 4 reviews various conventional capping methods such as TEOS(Tetra Ethyl Ortho Silicate), thermal oxide and amorphous silicon oxynitride suggesting making the film surface oxidic could provide with the solution for scum and footfree resist profiles.

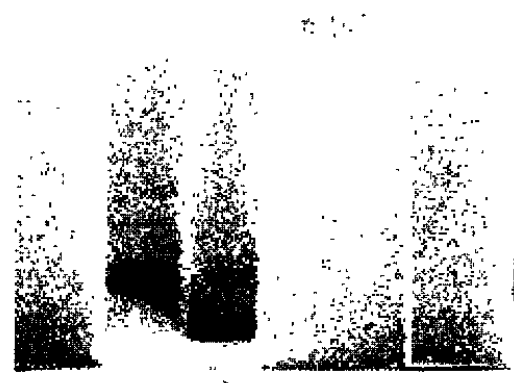

a)

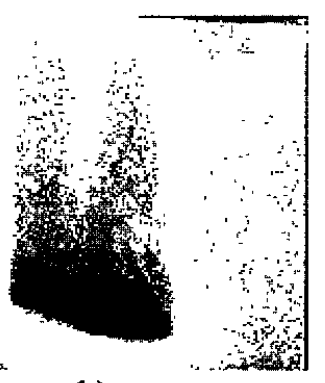

b)

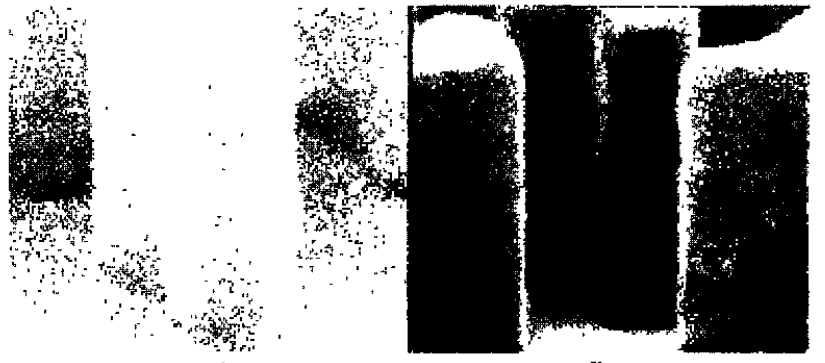

c)

d)

Fig.4 Profiles of resist on various surface treated $\mathrm{Si}_{3} \mathrm{~N}_{4}$ : a) TEOS, b) MTO, c) silicon oxynitride. d) oxygen plasma

It has been known that acid pretreatment to silicon nitride film lead to the formation of very thin oxide layer on which patterning works were carried out. The acid used, called clean D treatment for resist strip, usually consists of a mixture of sulphuric acid( $80 \%$ water) and hydrogen peroxide( $80 \%$ water). As seen in fig. 5 resist scum and foot disappeared completely regardless of resists used. Another method is oxygen plasma treatment which were carried out on PECVD(Plasma Enhanced CVD) furnace. The same results were obtained(see fig. 4d).

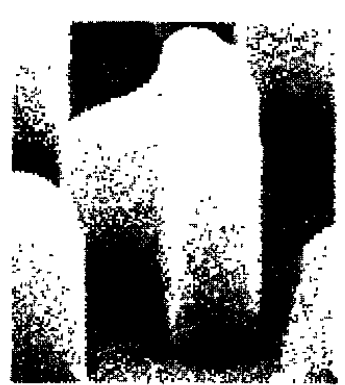

a)

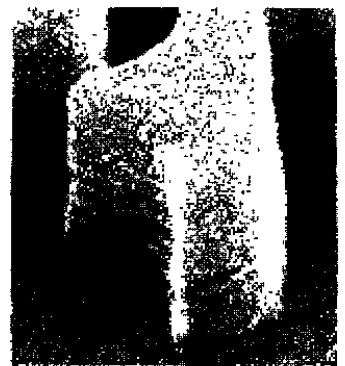

b)

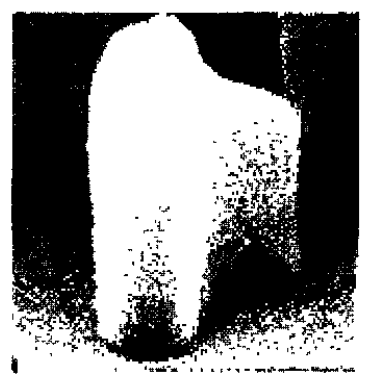

c)

Fig. 5 Profiles of three different resists on $\mathrm{Si}_{3} \mathrm{~N}_{4}$ after acid trealment 
Table 1 listed the ESCA analysis of acid and oxygen plasma treatment. From the table 1 it is found that $10.2 \%$ increase of oxygen ratio by acid treatment can work effectively as a capping layer and the results of oxygen plasma treatment matched well with Usujima's analysis. The only difference from their experiment is that we used PECVD furnace which is more effective and time-saving process.

Table 1 Summary of ESCA analysis

\begin{tabular}{lcccc}
\multicolumn{1}{c}{ atoms } & $\mathrm{O}(1 \mathrm{~s})$ & $\mathrm{N}(1 \mathrm{~s})$ & $\mathrm{C}(1 \mathrm{~s})$ & $\mathrm{Si}(2 \mathrm{p})$ \\
$\begin{array}{l}\text { methods } \\
\text { reference }\end{array}$ & & & & \\
$\mathrm{Si}_{3} \mathrm{~N}_{4}$ & $13.9 \%$ & $37.7 \%$ & $3.3 \%$ & $45.1 \%$ \\
acid treated & & & & \\
$\mathrm{Si}_{3} \mathrm{~N}_{4}$ & $24.1 \%$ & $27.8 \%$ & $1.9 \%$ & $43.9 \%$ \\
$\mathrm{O}_{2}$ plasma & $52.1 \%$ & $12.7 \%$ & $1.6 \%$ & $42.1 \%$ \\
treated $\mathrm{Si}_{3} \mathrm{~N}_{4}$ & $(48.3)$ & $(16.6)$ & $\begin{array}{l}(4.6) \\
(30.1)\end{array}$ \\
& & & () Usujima et al $[4]$
\end{tabular}

However, these two methods, unlike the conventional oxide capping methods, have a limited storage time. In the case of acid treatment after 48 hours storage time resist scums and foot appeared suddenly and after 5 days on oxygen plasma treated films as shown in fig.6. Though it is not fully understood, it could be speculated that unlike the conventional thick oxide film, the formed thin oxide layer by acid and oxygen plasma treatment is more likely to absorb moisture.
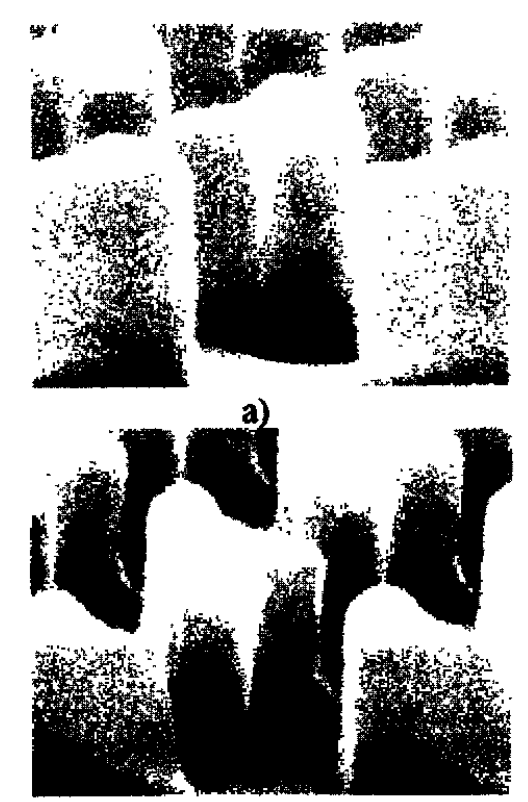

b)
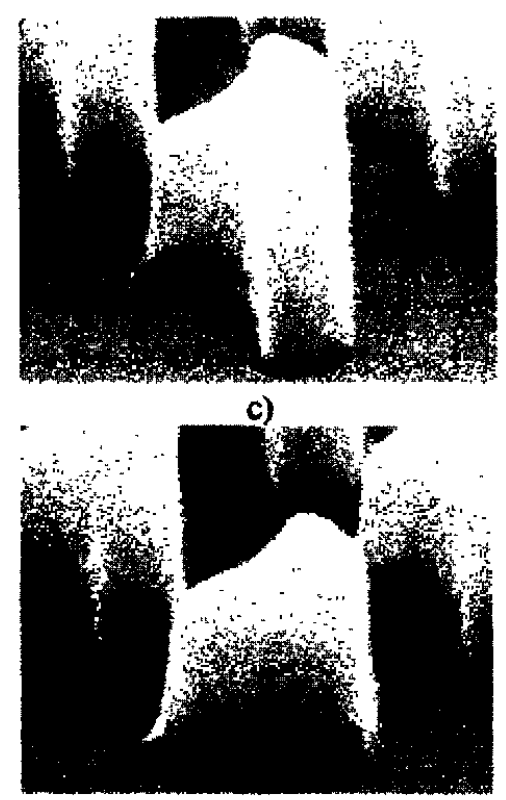

d)

Fig.6 Resist profiles on; acid(a,b) and $\mathrm{O}_{2}$ plasma(c,d) treated $\mathrm{Si}_{3} \mathrm{~N}_{4}$ a, c) No storage time, b) 48 hours of storage time, d) 5 days of storage time

To validate the speculation dehydration bake was carried out to find " resist scum and foot has gone away again!". The detailed analysis is under development. Table 2 summarized the results of various surface pretreatment methods comparing the time to process 25 wafers and their storage time. As a results, conventional oxide capping methods could be appreciated at the point of process stability. In terms of the cost of ownership, process simplicity and delay time stability, acid and oxygen plasma treatments are highly recommendable.

Table 2 Summary of various treatment on $\mathrm{Si}_{3} \mathrm{~N}_{4}$

$\begin{array}{ccccc} & \begin{array}{c}\text { bare } \\ \mathrm{Si}_{3} \mathrm{~N}_{4}\end{array} & \text { acid } & \mathrm{O}_{2} & \text { capping } \\ \text { scum } & \mathrm{scum} & \text { no } & \text { no } & \text { no } \\ \text { foot } & \text { foot } & \text { no } & \text { no } & \text { no } \\ \text { storage time } & - & <48 \mathrm{H} & <5 \mathrm{Day} & <\mathbf{3 0 ~ D a y} \\ \text { process time } & - & <1 \mathrm{H} & <1 \mathrm{H} & <2 \mathrm{H} \\ \text { (25wafers/hour) } & & & & \end{array}$

\subsection{BPSG films}

Fig. 7 shows the typical resist foot on BPSG film and fig. 8 the improved resist profiles on surface pretreated BPSG film. Even though the mechanism of the foot formation on BPSG film still remains unknown, improved resist profiles can be obtained on oxide capped layer like silicon nitride film. 


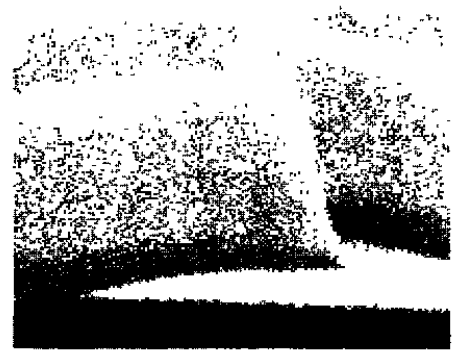

a)

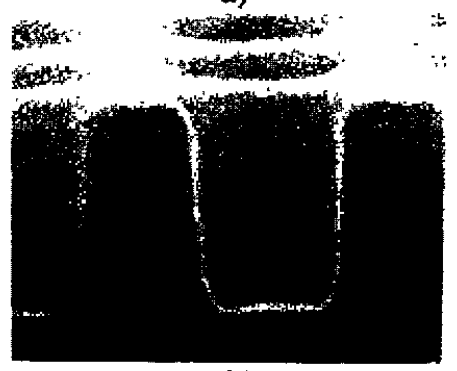

b)

Fig. 7 Cross-sectional SEM micrographs on BPSG films; a) island pattern b) contact hole

J. Sakakida et al studied the atmospheric ammonia and ammonium ion absorption of BPSG film and postulated that the absorbed ammonia onto the BPSG film might cause positive CA resist foot.[6] It led us that dehydration bake before resist coating could be applied to BPSG film. As seen in fig. 8b, resist profile seems to be improved but the foot has not disappeared completely.

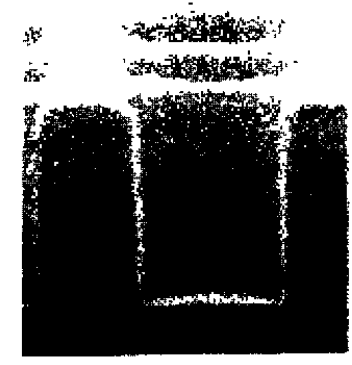

a)

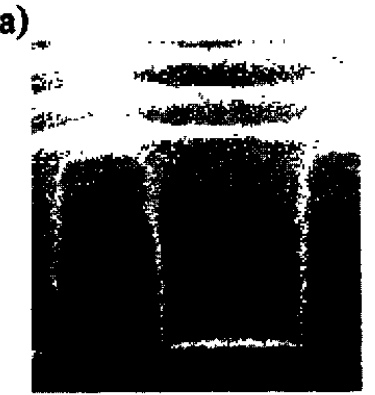

c)

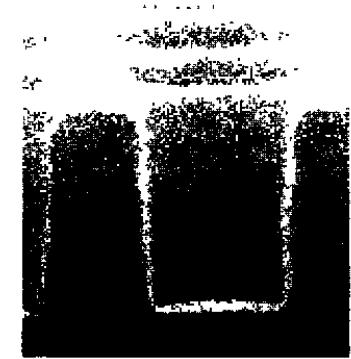

b)
Fig. 8 Cross-sectional SEM micrographs on surface treated BPSG films; a) TEOS, b) dehydration bake, c) $\mathrm{O}_{2}$ plasma
Acid treatment method should not be used because of the contamination by out-diffusion of boron and phosphorrous which lead to surface damage. The cost of ownership of conventional oxide capping method, compared to the oxygen plasma treatment and dehydration baking method, is higher because of the use of additional gases. Like mentioned at silicon nitride film, oxygen plasma treated and dehydrated BPSG films has limited storage time, 5 days and 36 hours. Table 3 shows the results and process conditions of various surface pretreatment on BPSG film. It can be concluded that oxygen plasma treatment and dehydration baking methods is the best solution at the points of process cost of ownership and stability.

Table 3 Summary of surface treatments on BPSG

$\begin{array}{lcccc} & \text { bare BPSG } & \mathrm{O}_{2} & \text { capping } & \text { bake } \\ \text { scum } & \text { no } & \text { no } & \text { no } & \text { no } \\ \text { foot } & \text { foot } & \text { no } & \text { no } & \text { no } \\ \text { storage } & - & <5 \mathrm{D} & <30 \text { Days } & <36 \mathrm{H} \\ \text { time } & & & & \\ \text { process } & & & & \\ \text { time(25 } & - & <1 \mathrm{H} & <2 \mathrm{H} & <1.5 \mathrm{H} \\ \text { wafers/h) } & & & & \end{array}$

\section{Conclusions}

Various surface pretreatment methods were evaluated. In the case of silicon nitride, acid and oxygen plasma treatment methods were found to be very effective, economical and simple process and on BPSG film dehydration bake before resist coating was helpful and oxygen plasma method is best solution. Unlike the conventional thick oxide capping layer, acid or oxygen plasma treated silicon nitride and BPSG films(also dehydration bake) have a limited storage time with a range of 36 hours to 5 days. These delay time effects do not influence on real device process at all. The detailed analysis are under development. Conventional capping methods might be acceptable only for the process stability. But the process complexity and particle generation could be a burden to device application.

For the process integration, simplicity and cost of ownership, acid and oxygen plasma treatments on silicon nitride films, dehydration bake and oxygen plasma treatment on BPSG films should be highly applicable to real device process. With uses of various surface pretreating methods, synchronous $256 \mathrm{M}$ bit DRAM has been successfully fabricated. 


\section{Acknowledgment}

The author(JSC) wish to thank ASM lithography, for their providing financial support of attending this conference. And also Andrew for his interest in this work.

\section{Reference}

1. J. C. Vigil et al., Proc. SPIE 2438, p. 628(1995)
2. O. Nalmasu et al., J. Vac. Sci. Technol. 1310(6), p. 2536(1992)

3. H. Ito et al., Proc. SPIE 1925, p. 65(1993)

4. A. Usujima et al., Proc. SPIE 2438, p. 529(1995)

5. K. R. Dean et al., Proc. SPIE 2438, p. 514(1995)

6. J. Sakakida et al., The $18^{\text {th }}$ international symphosium for testing \& failure analysis, LA, CA, p. $259,17-23$ oct, (1992) 